Case Report

\title{
Combined Treatment of a Gallbladder Volvulus with a Common Bile Duct Obstruction
}

\author{
M. Laydi, K. Charpentier, B. Paquette, and B. Heyd \\ Surgery Department, CHU Besançon, 25000 Besançon, France \\ Correspondence should be addressed to M. Laydi; laydi.maxime@gmail.com
}

Received 5 December 2016; Accepted 26 March 2017; Published 30 April 2017

Academic Editor: Hajime Imura

Copyright (C) 2017 M. Laydi et al. This is an open access article distributed under the Creative Commons Attribution License, which permits unrestricted use, distribution, and reproduction in any medium, provided the original work is properly cited.

Gallbladder volvulus is a rare disease and can lead to an acute cholecystitis. We report the case of an elderly woman with a gallbladder volvulus, diagnosed at CT scan and treated by surgery and endoscopic sphincterotomy.

\section{Introduction}

Gallbladder volvulus is defined by a gallbladder rotation around its mesentery along the axis of the cystic duct and artery [1]. Torsion occurs when "free-floating" gallbladder twists around its pedicle, leading to an obstruction of biliary drainage and blood flow [2]. This disease course is gangrenous gallbladder and biliary peritonitis. Initially described by Wendel in 1898 [3], the gallbladder volvulus is a relatively rare entity [4]. With approximately 500 cases described in literature [5] most of them were reported in elderly people with a ratio female-to-male of $3: 1$ [6].

\section{Case Report}

An 89-year-old woman was admitted to our hospital. Her reason for admission was an acute pain from the right hypochondriac region and constipation. The patient's past medical history included a severe hypertensive and valvular heart disease, chronic kidney failure, right carotid stenosis, hiatal hernia, colon angiodysplasia, and a Raynaud's syndrome. Her surgical history included rectocele cure and appendectomy. The spasmodic pain was localized at the right hypochondriac region since less than 24 hours. At admission her temperature was $36.3^{\circ} \mathrm{C}$, her pulse was $58 \mathrm{bpm}$, and blood pressure was $146 / 69 \mathrm{mmHg}$. Her BMI was $19 \mathrm{~kg} / \mathrm{m}^{2}$. Physical examination showed right hypochondriac Murphy's sign with defense but no contracture. There was no jaundice. The patient was not nauseous. Biology showed a leukocyte count of $14.2 \times 10^{9} / \mathrm{L}$ (normal, $4-10 \times 10^{9} / \mathrm{L}$ ) a $\mathrm{C}$ reactive protein of $25.6 \mathrm{mg} / \mathrm{L}$ (normal, $<8 \mathrm{mg} / \mathrm{L}$ ). Full liver function test was normal. Serum lipase level was normal. She had a hyponatremia of $127 \mathrm{mmol} / \mathrm{L}$ (normal, 135-145 mmol/L) and an normocytic anemia of $10.9 \mathrm{~g} / \mathrm{dL}$ (normal, $12-16 \mathrm{~g} / \mathrm{dL}$ ). A CT scan with was realized with contrast injection. Cholecystitis was revealed by a gallbladder enlargement (Figure 1) with intraluminal hemorrhage (Figure 2), wall thickening, and free fluid. No stones were detected. Focal enhancement defects (Figure 1) suggested ischemic phenomena and preperforative gallbladder. Torsion was revealed by a whirl sign [7] of the cystic pedicle (Figure 3 ) and lateral position of the gallbladder neck. This abnormal configuration is one of the most evocative signs of gallbladder volvulus. An emergency laparoscopic cholecystectomy with a rendezvous technique was performed. Surgery revealed a necrotic gallbladder, rotated to 720 degrees clockwise around its mesentery (Figure 4). Detorsion and cholecystectomy were performed with success. Peroperative cholangiography showed gallstones impacted in the proximal part of the bile duct. Duct cannulation and sphincterotomy by electrosurgical division of papilla was done. The $1 \mathrm{~cm}$ gallstone was retrieved with a balloon sweep and the procedure was finished by the set-up of a suction drainage. Pathological examination revealed a $9,5 \mathrm{~cm}$ necroinflammatory and hemorrhagic gallbladder. There was no sign of malignancy and it was stone free. Global cardiac failure from an acute coronary syndrome worsened during her postoperative course; medical management could not avoid her death on postoperative day 12 . 


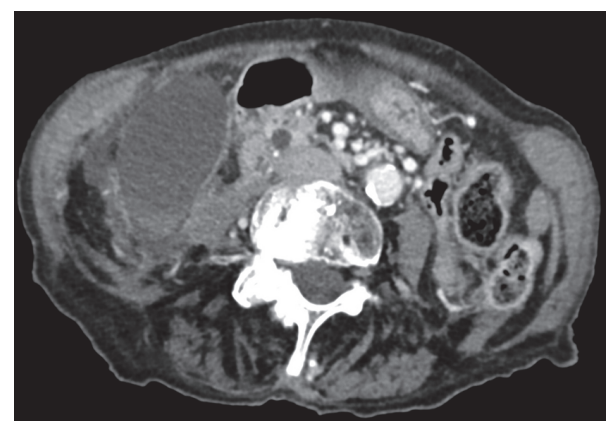

FIgURE 1: Abdominal contrast enhanced CT scan, portal phase distended gallbladder with focal enhancement defect.

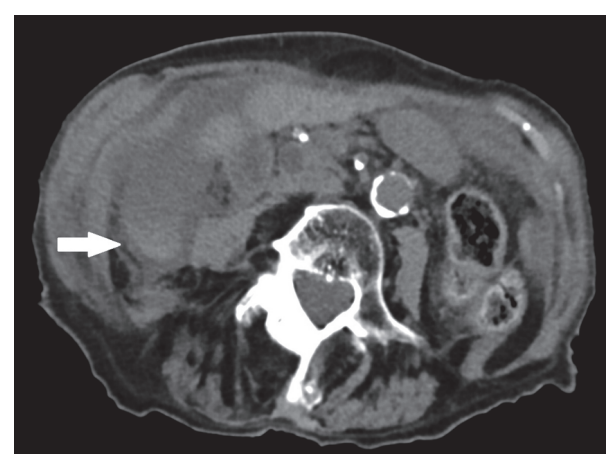

Figure 2: Abdominal unenhanced CT scan: high attenuation area, suggesting an intraluminal hemorrhage.

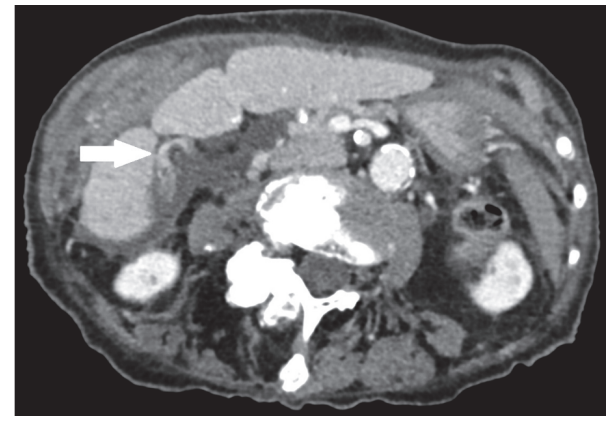

FIgURE 3: Abdominal contrast enhanced CT scan, portal phase: "Whirl sign" of the gallbladder pedicle.

\section{Conclusion}

Sudden cholecystitis symptoms, particularly in elderly patient with a few risk factors should always evoke a gallbladder volvulus. The prompt diagnosis is crucial to ensure that the patient undergoes an emergent cholecystectomy rather than temporizing measures with antibiotics. Risks factors and pathology results should help lead to this diagnostic. The patient medical history showed many contributing factors [8] as an iatrogenic manipulation of the abdomen (She had a coloscopy 8 weeks before), colon angiodysplasia, malnutrition, and hiatal hernia. Other risks factors [8] are anatomic variants like an unusually long mesentery, hypermobile liver, or kyphoscoliosis. Gallstones

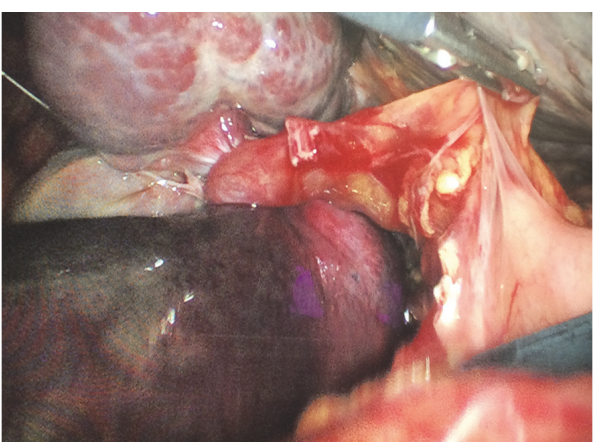

FIGURE 4: Laparoscopic view.

are not a risk factor, only reported from 20 to $33 \%$ of cases [9]. However diagnosis remains difficult and no imaging mean has proven to be sufficiently sensitive [9].

\section{Conflicts of Interest}

The authors declare that there are no conflicts of interest regarding the publication of this paper.

\section{References}

[1] V. Malherbe, A. C. Dandrifosse, N. Detrembleur, and A. Denoel, "Torsion of gallbladder: two case reports," Acta Chirurgica Belgica, vol. 108, pp. 130-132, 2008.

[2] A. M. Morales and A. H. Tyroch, "Wandering gallbladder," American Journal of Surgery, vol. 196, no. 2, pp. 240-241, 2008.

[3] A. V. Wendel, "A case of floating gallbladder and Kidney complicated by cholelithiasis with perforation of the gallbladder," Annals of Surgery, vol. 27, pp. 199-202, 1898.

[4] A. Nakao, T. Matsuda, S. Funabiki et al., "Gallbladder torsion: case report and review of 245 cases reported in the Japanese literature," Journal of Hepato-Biliary-Pancreatic Surgery, vol. 6, no. 4, pp. 418-421, 1999.

[5] O. R. Tahran, I. Barut, and H. Dinelek, "Gallbladder volvulus: review of the literature and report of a case," The Turkish Journal of Gastroenterology, vol. 17, no. 3, pp. 209-211, 2006.

[6] N. Matsuhashi, S. Satake, K. Yawata et al., "Volvulus of the gall bladder diagnosed by ultrasonography, computed tomography, coronal magnetic resonance imaging and magnetic resonance cholangio-pancreatography," World Journal of Gastroenterology, vol. 12, no. 28, pp. 4599-4601, 2006.

[7] Y. Tajima, N. Tsuneoka, T. Kuroki, and T. Kanematsu, “Gallbladder torsion showing a "whirl sign" on a multidetector computed tomography scan," American Journal of Surgery, vol. 197, no. 1, pp. e9-e10, 2009.

[8] W. A. Newman Dorland, Dorland'S Illustrated Medical Dictionary, WD Saunders, Philadelphia, PA, USA, 30th edition, 2003.

[9] N. J. Mouawad, B. Crofts, R. Streu, R. Desrochers, and B. C. Kimball, "Acute gallbladder torsion-a continued pre-operative diagnostic dilemma," World Journal of Emergency Surgery, vol. 6, no. 1, article 13, 2011. 


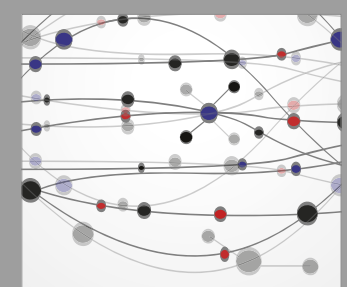

The Scientific World Journal
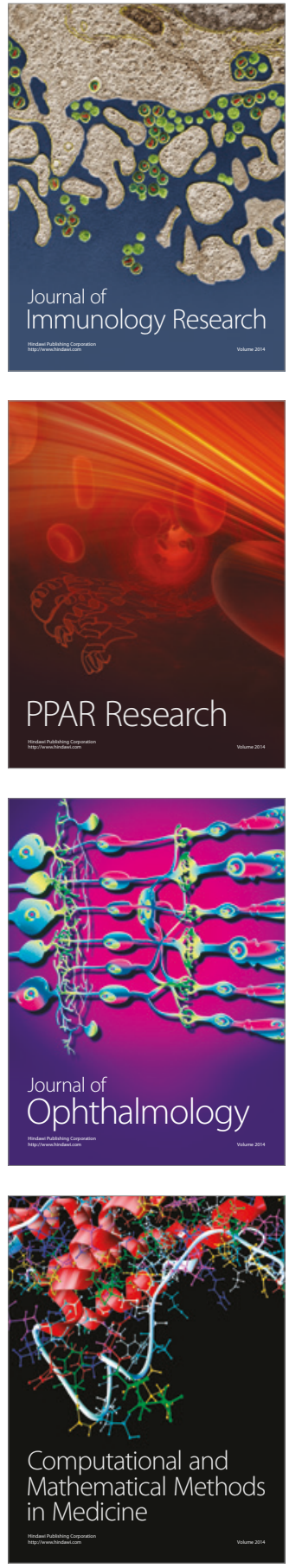

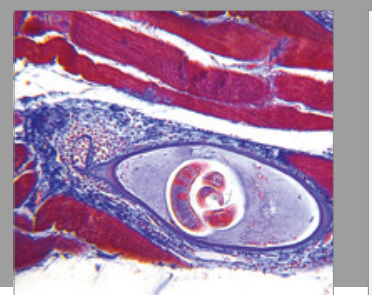

Gastroenterology Research and Practice
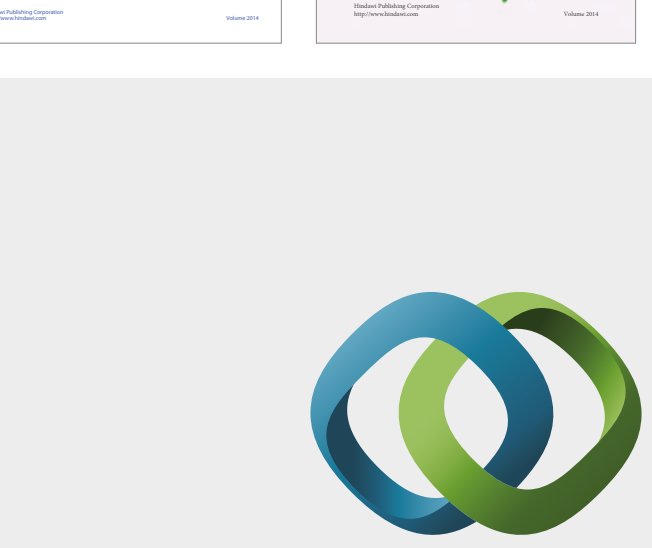

\section{Hindawi}

Submit your manuscripts at

https://www.hindawi.com
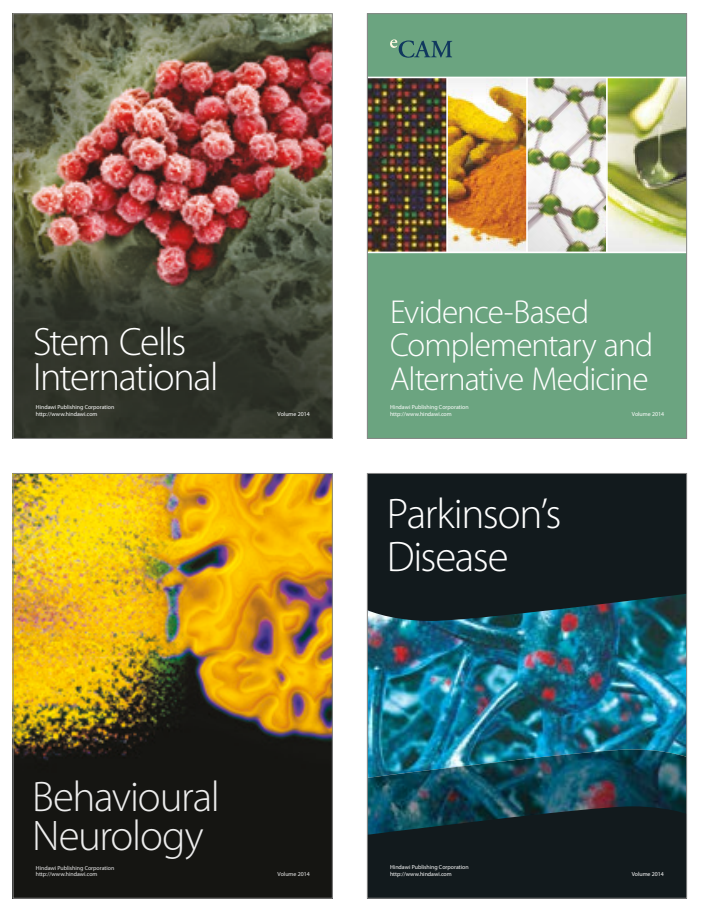
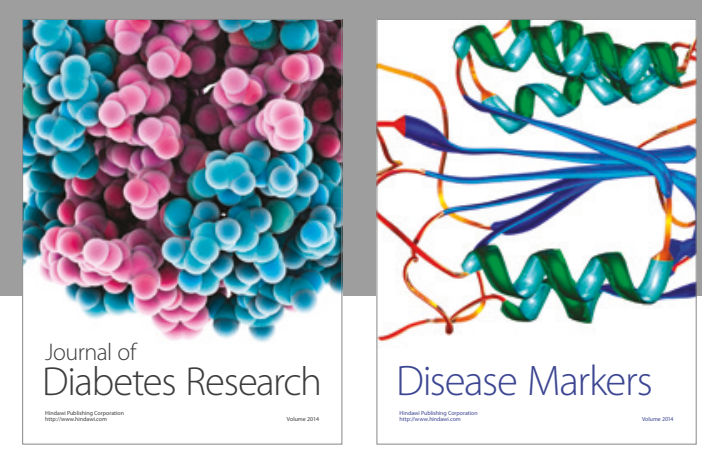

Disease Markers
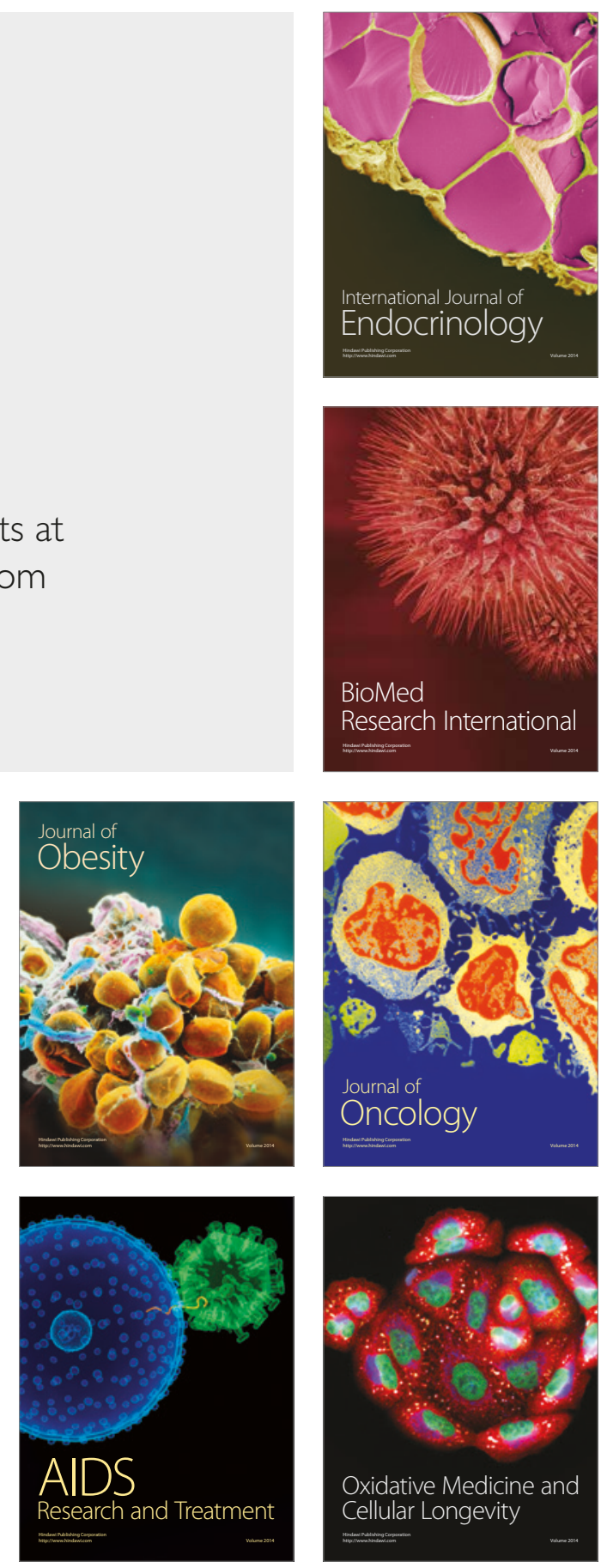